\title{
EFEITO DA ESCALA DE PRODUÇÃO NA RENTABILIDADE DA TERMINAÇÃO DE BOVINOS DE CORTE EM CONFINAMENTO
}

\author{
Effect of the production scale in the profitability of finishing \\ feedlot beef cattle in feedlot
}

\author{
Marcos Aurélio Lopes ${ }^{1}$, Glauber dos Santos ${ }^{2}$, \\ Gustavo Pires Magalhães ${ }^{3}$, Francisval de Melo Carvalho ${ }^{4}$
}

\begin{abstract}
RESUMO
Com este estudo, objetivou-se analisar o efeito da escala de produção na rentabilidade da terminação de bovinos de corte em confinamento e identificar os componentes que exerceram maior influência sobre os custos finais da atividade. Os dados analisados são provenientes da simulação de confinamentos de 100, 500 e 1000 bovinos machos castrados, durante os meses de maio a agosto de 2005. O processamento dos dados foi realizado utilizando uma planilha eletrônica. Diante dos resultados, concluiu-se que a escala de produção afetou significativamente a lucratividade da atividade, e que os itens componentes do custo operacional efetivo que exerceram maior influência sobre os custos da atividade confinamento foram, em ordem decrescente, aquisição dos animais, alimentação, despesas diversas, mão-de-obra, sanidade e impostos.
\end{abstract}

Termos para indexação: Custo de produção, lucratividade, pecuária de corte, simulação.

\begin{abstract}
This study had the objective to analyze the effect of production scale in the profitability of finishing beef cattle production in feedlot conditions and identify the components that had higher influence on the final costs of the activity. The analyzed data originated from the simulation of finishing 100, 500 and 1000 male castrated bovines, from May 2005 to August 2005. The data was processed by using an electronic spreadsheet. Accord to the results, it was conclude that the production scale affected significantly the profitability of the finishing beef cattle production in feedlot and that the items of the effective operational cost had greater influence on the costs of the activities were, in a decreasing sequence order of importance, the purchasing of the animals, feed, several expenses, labor, health care and taxes.
\end{abstract}

Index terms: Analysis of profitability, beef cattle, production cost, simulation.

(Recebido para publicação em 15 de julho de 2005 e aprovado em 28 de dezembro de 2005)

\section{INTRODUÇÃO}

A bovinocultura é uma importante atividade econômica para o Brasil, que de acordo com o Instituto Brasileiro de Geografia e Estatística possui 195.551.576 cabeças de animais. Lopes \& Sampaio (1999) salientaram que tem havido uma preocupação, por parte dos pecuaristas, em explorar mais intensivamente suas propriedades, buscando maior produtividade $\mathrm{e}$ lucratividade. Esses mesmos pesquisadores mencionaram um crescimento de $110 \%$ no número de animais confinados durante o período de 1990 a 1997. De acordo com o ANUALPEC (2004), o número de animais confinados, durante o período de 1995 a 2003 , cresceu $61,8 \%$.

A pecuária de corte, nos últimos anos, tem valorizado o planejamento, o controle, a gestão produtiva e empresarial das fazendas (LACORTE, 2002). Segundo Antonialli (1998), administrar uma empresa rural resume-se em exercer as funções de planejar, organizar, dirigir e controlar os esforços de um grupo de pessoas, visando atingir objetivos previamente determinados que podem ser a sobrevivência, o crescimento, o lucro, o prestígio ou o prejuízo.

De acordo com Nogueira (2004), o produtor deve se profissionalizar por completo, ou seja, deve adotar todas as técnicas e procedimentos modernos de modo que produza com eficiência, buscando escala e redução de custos. De acordo com Lopes \& Carvalho (2002), analisar economicamente a atividade gado de corte é extremamente importante, pois por meio dela o produtor passa a conhecer com detalhes e a utilizar, de maneira inteligente e econômica, os fatores de produção. A partir daí, localiza os pontos de estrangulamento, para depois concentrar esforços gerenciais e tecnológicos, para obter sucesso na sua atividade e atingir os seus objetivos de maximização de lucros ou minimização de custos.

${ }^{1}$ D.Sc, Professor do Departamento de Medicina Veterinária da Universidade Federal de Lavras/UFLA - Cx. P. 3037 - $37200-000$ - Lavras, MG malopes@ufla.br

${ }^{2}$ Graduando em zootecnia pela Universidade Federal de Lavras/UFLA - Cx. P. 3037 - 37200-000 - Lavras, MG - glauber_zoo@yahoo.com.br

${ }^{3}$ Zootecnista - Universidade Federal de Lavras/UFLA - Cx. P. 3037 - 37200-000 - Lavras, MG - gupima@yahoo.com.br

${ }^{4}$ Professor do Departamento de Administração e Economia da Universidade Federal de Lavras/UFLA-Cx. P. 3037 - 37200-000 - Lavras, MG - francarv@ufla.br 
Vários pesquisadores têm se preocupado em estudar diferentes aspectos da terminação de bovinos de corte em confinamento, tais como a nutrição (alimentos alternativos), instalações, tipos raciais, sexo e idade dos animais. Entretanto, poucos estudos têm sido realizados sobre a viabilidade econômica dessa atividade e os fatores que influenciam sua rentabilidade. Dentre tais fatores está a escala de produção.

Existe economia de escala quando a expansão da capacidade de produção de uma firma ou indústria causa um aumento dos custos totais de produção menor que, proporcionalmente, os do produto. Como resultado, os custos médios de produção caem, a longo prazo (BANNOCK et al., 1977). O efeito economia de escala é percebido à medida em que aumenta-se a produção, mantendo-se constantes os custos fixos. Nessas condições, percebe-se que ocorrerá uma redução do custo médio unitário, por arroba de carne, devido à diluição dos custos fixos por uma maior quantidade de produto.

Os objetivos desta pesquisa foram analisar os efeitos da escala de produção na rentabilidade da terminação de bovinos de corte em confinamento, bem como identificar os componentes que exercem maior influência sobre o custo de produção.

\section{MATERIAL E MÉTODOS}

Os dados referentes ao uso de insumos e à infraestrutura utilizada nos sistemas de produção de 100, 500 e 1000 bovinos de corte foram aqueles utilizados por Lopes \& Sampaio (1999). Os preços dos insumos, bem como do boi magro ( $\mathrm{R} \$ 50,00 / @)$, foram atualizados considerando o mercado no município de Lavras, MG, na segunda quinzena de abril de 2005. A estimativa do valor de venda no mercado futuro para setembro de 2005, de R\$61,01 / @, foi obtido em

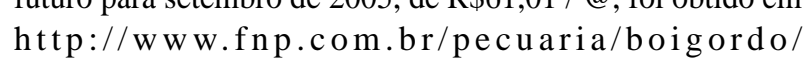
Imercado_futuro.php. O ciclo de engorda foi de 100 dias. Na simulação, os animais (mestiços machos castrados), que pesaram em média $350 \mathrm{~kg}$ de peso vivo no início do confinamento, foram vermifugados e vacinados contra aftosa.

A dieta total foi balanceada para que os animais tivessem um ganho de peso diário de $1,1 \mathrm{~kg}$ (Tabela 1), utilizando-se o software Super Crac Bovinos Corte (TD Software). Os alimentos disponibilizados para o referido software balancear as dietas, a custo mínimo, foram silagem de milho, cana-de-açúcar, carroço de algodão, farelo de soja, milho desintegrado, uréia, calcário calcítico, fosfato bicálcico e farelo de algodão. Tais dietas foram distribuídas aos animais duas vezes por dia. Os minerais foram fornecidos na própria dieta total. O sal comum foi fornecido à vontade em cochos dentro dos currais de engorda.

Os cálculos do custo de produção contemplaram duas estruturas de custo: Custo Total de Produção - CT (clássica), que envolve o custo fixo (CF) e custo variável (CV), utilizada por Barros (1948), e Custo Operacional Total (COT) (refere-se ao custo de todos os recursos de produção que exigem desembolso por parte do produtor), proposta por Matsunaga et al. (1976) e adotada pelo Instituto de Economia Agrícola - IEA/SP (MATSUNAGA et al., 1976). A metodologia utilizada nos cálculos da margem bruta (receita bruta menos custo operacional efetivo - COE), margem líquida (receita bruta menos custo operacional total), ponto de equilíbrio, lucratividade ((lucro líquido / receita) $x$ 100) e a rentabilidade ((lucro líquido / investimento total) x 100) foi a utilizada por Lopes \& Carvalho (2002). A depreciação foi calculada pelo método linear (HOFFMANN et al., 1981).

TABELA 1 - Composição da ração utilizada na alimentação dos animais.

\begin{tabular}{|c|c|c|c|}
\hline Alimento & $\begin{array}{l}\text { Mat. Seca } \\
\text { (kg/dia) }\end{array}$ & $\begin{array}{c}\text { Matéria natural } \\
(\mathrm{kg} / \mathrm{dia})\end{array}$ & $\%$ na mistura \\
\hline \multicolumn{4}{|l|}{ Volumoso } \\
\hline Cana-de-açúcar & 5,250 & 22,629 & 100,000 \\
\hline Sub- total & 5,250 & 22,629 & 100,000 \\
\hline \multicolumn{4}{|l|}{ Concentrado } \\
\hline Caroço de algodão & 3,200 & 3,478 & 97,580 \\
\hline Calcário & 0,045 & 0,045 & 1,260 \\
\hline Uréia & 0,037 & 0,041 & 1,150 \\
\hline Sub- total & 3,282 & 3,564 & 100,000 \\
\hline Total (kg) & 8,532 & 26,193 & 100,000 \\
\hline
\end{tabular}


Os itens que compõem o Custo Operacional Efetivo de produção do gado de corte (aqueles nos quais ocorre efetivamente desembolso ou dispêndio em dinheiro) foram divididos em grupos: mão-de-obra, alimentação, sanidade, aquisição de animais, impostos e despesas diversas (LOPES et al., 1999). Nessa pesquisa, as despesas referentes à energia elétrica e combustíveis, foram separadas do grupo despesas diversas, sendo então computadas separadamente.

O processamento dos dados foi realizado utilizando uma planilha eletrônica desenvolvida especialmente para este fim. Os resultados foram comparados por meio de análise descritivas, e agrupados em tabelas, objetivando uma melhor comparação, discussão e apresentação dos resultados (LOPES et al., 2004a).

\section{RESULTADOS E DISCUSSÃO}

O resumo das análises de rentabilidade da terminação em confinamento de 100, 500 e 1000 bovinos de corte pode ser observado na Tabela 2 . A receita total foi de $\mathrm{R} \$ 99.903,18, \quad \mathrm{R} \$ 499.515,90$ e $\mathrm{R} \$ 999.031,80$ para os confinamentos de 100, 500 e 1000 animais, respectivamente, correspondendo a soma dos valores apurados com a venda dos animais $(92,7 \%)$ e o esterco $(7,3 \%)$.

TABELA 2 - Resumo da análise de rentabilidade (em R \$), da terminação de bovinos em confinamento, com diferentes escalas de produção (100, 500 e 1000 cabeças).

\begin{tabular}{|c|c|c|c|}
\hline \multirow[b]{2}{*}{ Especificação } & \multicolumn{3}{|c|}{ Quantidade de animais } \\
\hline & 100 & 500 & 1000 \\
\hline 1) receitas & $99.903,18$ & $499.515,90$ & $999.031,80$ \\
\hline 2) custo operacional total $(3+4)$ & $82.748,06$ & $394.581,99$ & $774.804,20$ \\
\hline 3) total custo operacional efetivo & $79.567,77$ & $386.989,55$ & $766.063,80$ \\
\hline 4) custo com depreciação & $3.180,29$ & $7.592,44$ & $8.740,40$ \\
\hline 5) custo total $(6+11)$ & $87.619,74$ & $410.816,27$ & $800.510,48$ \\
\hline 6) custos fixos $(7+8+9+10)$ & $6.460,61$ & $16.086,92$ & $19.125,41$ \\
\hline 7) custo com depreciação & $3.180,29$ & $7.592,44$ & $8.740,40$ \\
\hline 8) remuneração da terra & 325,59 & $1.139,94$ & $1.936,78$ \\
\hline 9) remuneração do capital investido & $2.594,74$ & $6.994,55$ & $8.088,23$ \\
\hline 10) remuneração do empresário & 360,00 & 360,00 & 360,00 \\
\hline 11) custos variáveis $(12+13)$ & $81.159,13$ & $394.729,34$ & $781.385,07$ \\
\hline 12) custo operacional efetivo sem impostos & $79.567,77$ & $386.989,55$ & $766.063,80$ \\
\hline 13) remuneração sobre capital de giro & $1.591,36$ & $7.739,79$ & $15.321,28$ \\
\hline 14) margem bruta (1-3) & $20.335,41$ & $112.526,35$ & $232.968,00$ \\
\hline 15) margem líquida (1-2) & $17.155,12$ & $104.933,91$ & $224.227,60$ \\
\hline 16) resultado (lucro ou prejuízo) (1-5) & $12.283,44$ & $88.699,63$ & $198.521,32$ \\
\hline 17) custo operacional efetivo / @ (3/26) & 52,42 & 50,99 & 50,47 \\
\hline 18) custo operacional total / @ (2/26) & 54,51 & 51,99 & 51,04 \\
\hline 19) custo variável médio / @ (11/26) & 53,46 & 52,01 & 51,47 \\
\hline 20) custo total / @ (5/26) & 57,72 & 54,13 & 52,73 \\
\hline 21)preço@ & 61,01 & 61,01 & 61,01 \\
\hline 22) lucratividade $(\%)$ & 12,30 & 17,76 & 19,87 \\
\hline 23 ) rentabilidade $(\%)$ & 9,79 & 17,29 & 21,61 \\
\hline 24) \% do custo fixo em relação CT (6/5) & 7,37 & 3,92 & 2,39 \\
\hline 25) \% do custo variável em relação CT (11/5) & $92,63 \%$ & $96,08 \%$ & $97,61 \%$ \\
\hline 26) produção total de @ & $1.518,00$ & $7.590,00$ & $15.180,00$ \\
\hline 27) ponto de equilíbrio ( @ ) & 856,22 & $1.786,74$ & $2.005,74$ \\
\hline 28) dif. total - ponto equilib.(@) & 661,78 & $5.803,26$ & $13.174,26$ \\
\hline
\end{tabular}

Ciênc. agrotec., Lavras, v. 31, n. 1, p. 212-217, jan./fev., 2007 
O custo operacional total foi de $\mathrm{R} \$ 82.748,06$, $\mathrm{R} \$ 394.581,99$ e $\mathrm{R} \$ 766.063,80$ para os confinamentos de 100 , 500 e 1000 animais, respectivamente, e foi obtido pela soma do custo operacional efetivo, que foi o desembolso, com o custo de depreciação dos bens patrimoniais. Embora não seja um desembolso, o valor referente à depreciação representa uma reserva de caixa que deveria ser feita para repor os bens patrimoniais (instalações, máquinas, equipamentos etc.) ao final de sua vida útil (LOPES \& CARVALHO, 2002). A receita do período permitiu que essa reserva fosse feita em todas as simulações. Isso significa que ao final da vida útil dos bens, em permanecendo constantes as condições atuais, o pecuarista teria recursos monetários para a aquisição de novos bens substitutos, não havendo uma descapitalização.

No presente estudo, a depreciação foi responsável por $3,84 \% ; 1,92 \%$ e $1,12 \%$ do custo operacional total (COT), para os confinamentos de 100500 e 1000 animais respectivamente (Tabela 2). Esses resultados demonstram que a escala de produção influenciou o custo operacional total de produção e, portanto, a lucratividade e a rentabilidade. Isso se deve à otimização da estrutura física da empresa: aumentando a escala de produção até determinados níveis, o custo operacional total por unidade é reduzido (LOPES et al., 2004b), o que pode ser evidenciado na Tabela 2. Lopes \& Magalhães (2005), estudando um sistema de produção de grande porte (3.583 animais), constataram que a depreciação representou 1,74\% do COT. Embora na literatura não exista informação sobre qual seria um bom valor para esse indicador, pode-se dizer que a eficiência de utilização dos bens do patrimônio dos sistemas de produção estudados nesta pesquisa foi inferior ao sistema estudado por esses pesquisadores, sob o ponto de vista da metodologia do Custo Operacional (MATSUNAGA et al., 1976).

O custo operacional efetivo representa o desembolso médio feito pelo produtor para custear a atividade no período. Os itens que compõem o custo operacional efetivo de produção foram divididos em grupos, cada qual responsável pelos percentuais encontrados na Tabela 3. A divisão das despesas em grupos, de acordo com Lopes et al. (1999), permite o monitoramento das despesas do sistema de produção, auxiliando o técnico e o produtor em uma análise mais detalhada.

A aquisição dos animais representou o maior percentual do total dos custos operacionais efetivos. Lopes \& Magalhães (2005) salientaram que esse alto percentual mostra que os pecuaristas devem dar uma atenção especial nesse quesito, pois uma pequena economia, sem deixar de lado a qualidade dos animais a serem confinados, representa uma redução considerável do custo operacional efetivo, que refletirá na lucratividade e na rentabilidade.

A alimentação foi o segundo componente que mais "pesou" nas despesas operacionais efetivas (Tabela 3). Assim como na aquisição dos animais, os pecuaristas devem concentrar esforços também no balanceamento da dieta, buscando fontes alternativas de alimentos que possam diminuir o custo da alimentação, tanto concentrada quanto volumosa. De acordo com Lopes (1997), uma opção para balancear rações, testando diferentes fontes de alimentos, é utilizar softwares desenvolvidos especificamente para esse fim.

A mão-de-obra foi o componente do custo operacional efetivo que teve a maior variação (Tabela 3). Tal fato deveu-se ao alto nível de mecanização (trator e vagão forrageiro) utilizado no arraçoamento dos confinamentos de 500 e 1000 animais, reduzindo assim a relação animal/ homem. No confinamento de 100 animais esse arraçoamento foi realizado utilizando carroça com tração animal, demandando assim maior quantidade de mão-de-obra.

O custo total, que foi de $\mathrm{R} \$ 87.619,74, \mathrm{R} \$ 410.816,27$ e $\mathrm{R} \$ 800.510,48$ para 100,500 e 1000 cabeças, respectivamente, representa a soma dos custos fixos e dos custos variáveis. Os custos variáveis são compostos pelo custo operacional efetivo, excetuando impostos considerados fixos (ITR e IPVA) e pela remuneração do capital de giro. Os custos fixos são compostos pela remuneração da terra, remuneração do capital investido, remuneração do empresário, impostos considerados fixos (ITR e IPVA) e depreciação do patrimônio (LOPES \& CARVALHO, 2002). Esses custos não representam desembolso (com exceção dos impostos), mas sim o que a atividade deveria remunerar para ser competitiva com outras atividades econômicas e não descapitalizar o pecuarista ao longo dos anos. Se esses custos não forem contemplados, o pecuarista poderá, a longo prazo, perder o patrimônio e se endividar (LOPES \& CARVALHO, 2002).

Pela análise de rentabilidade tem-se uma margem bruta (receitas menos custo operacional efetivo), positiva em todas as simulações. Tal resultado mostra que a atividade está cobrindo as despesas e sobreviverá, pelo menos a curto prazo. A margem líquida, que é a receita menos o custo operacional total, também foi positiva em todas as simulações, mostrando que a atividade é estável a médio prazo, com possibilidade de expansão. O resultado, que é a diferença entre as receitas e o custo total (custos fixos e custos variáveis), foi positivo em todas as simulações. Resultados positivos significam que a atividade foi lucrativa e se manterá a longo prazo. 
TABELA 3 - Contribuição dos componentes dos custos operacionais efetivos (COE), em \%, da terminação de 100,500 e 1000 bovinos em confinamento.

\begin{tabular}{lccc}
\hline \multicolumn{1}{c}{ Item componente do COE } & $\mathbf{1 0 0}$ & $\mathbf{5 0 0}$ & $\mathbf{1 0 0 0}$ \\
\hline Aquisição de animais & 73,31 & 75,37 & 76,15 \\
Alimentação & 20,97 & 21,56 & 21,78 \\
Mão-de-obra & 4,02 & 1,58 & 0,80 \\
Energia (elétrica e combustível) & 0,58 & 0,87 & 0,83 \\
Diversas & 0,81 & 0,38 & 0,21 \\
Sanidade & 0,30 & 0,25 & 0,24 \\
\hline Total custo operacional efetivo & 100,00 & 100,00 & 100,00 \\
\hline
\end{tabular}

As lucratividades e as rentabilidades podem ser observadas na Tabela 2. Observa-se que os melhores resultados, para ambos indicadores, foram obtidos nos confinamentos de 500 e 1.000 animais. Pela lucratividade, pode-se comparar o sistema em foco com outros sistemas de produção de bovinos de corte, analisando qual é o mais lucrativo e, pela rentabilidade, pode-se compará-lo com atividades alternativas, como, por exemplo, a caderneta de poupança (LOPES et al., 2004b).

\section{CONCLUSÕES}

Diante dos resultados concluiu-se que: a) a escala de produção influenciou o custo total de produção da arroba de carne e, portanto, a lucratividade e a rentabilidade, sendo que os sistemas de produção com maior escala apresentaram os menores custos totais unitários; b) a escala de produção influenciou os "pesos" dos itens componentes do custo operacional efetivo da atividade, sendo esses diferentes em cada um dos três estratos de produção; c) a análise econômica que apresentou margem líquida e resultado positivos nos três estratos de produção, mostrou que a atividade confinamento tem condições de produzir no médio prazo, e os pecuaristas estão se capitalizando.

\section{REFERÊNCIAS BIBLIOGRÁFICAS}

ANTONIALLI, L. M. Contabilidade gerencial agropecuária. In: ENCONTRO DE ATUALIZAÇÃO TÉCNICA EM PECUÁRIA LEITEIRA, 3., 1998, Jaboticabal, SP. Anais... Jaboticabal: [s.n.], 1998. p. 1-17.

ANUALPEC. Anuário da pecuária brasileira. São Paulo: FNP, 2004. 385 p.
BARROS, H. Economia Agrária. Lisboa: Livraria Sá da Costa, 1948.

BANNOCK, G. et al. The Penguin dictionary of economics. Middlesex: Penguin Books, 1977. 428 p.

HOFFMANN, R.; ENGLER, J. J. C.; SERRANO, O. Administração da empresa agrícola. 3. ed. São Paulo: Pioneira, 1981. 325 p.

LACORTE, A. J. F. Principais aspectos do confinamento de gado de corte no Brasil. In: SIMPÓSIO DE PECUÁRIA DE CORTE: NOVOS CONCEITOS NA PRODUÇÃO BOVINA, 2., 2002, Lavras. Anais... Lavras: UFLA, 2002. p. 81-107.

LOPES, D. de C. F. de; LOPES, M. A.; JUNQUEIRA, L. V.; CARVALHO, F. M.; ZAMBALDE, A. L. Desenvolvimento de um sistema computacional para determinação do custo de produção do gado de corte. Revista Brasileira de Agroinformática, [S.1.], v. 2, n. 2, p. 105-116, 1999.

LOPES, M. A. Informática aplicada à bovinocultura. Jaboticabal: FUNEP, 1997. 82 p.

LOPES, M. A.; CARVALHO, F. de M. Custo de produção do gado de corte. Lavras: UFLA, 2002. 47 p. (Boletim agropecuário, 47).

LOPES, M. A.; LIMA, A. L. R.; CARVALHO, F. de M.; REIS, R. P.; SANTOS, I. C.; SARAIVA, F. H. Controle gerencial e estudo da rentabilidade de sistemas de produção de leite na região de Lavras (MG). Revista Ciência e Agrotecnologia, Lavras, v. 28, n. 4, p. 883-892, 2004. 
LOPES, M. A.; LIMA, A. L. R.; CARVALHO, F. de M.; REIS, R. P.; SANTOS, I. C.; SARAIVA, F. H. Efeito da escala de produção nos resultados econômicos de sistemas de produção de leite na região de Lavras (MG). In: REUNIÃO ANUAL DA SOCIEDADE BRASILEIRA DE ZOOTECNIA, 41., 2004, Campo Grande. Anais... Campo Grande: [s.n.], 2004. CD-ROM.

LOPES, M. A.; MAGALHÃES, G. P. Análise da rentabilidade da terminação de bovinos de corte em confinamento: um estudo de caso. Arquivo Brasileiro de Medicina Veterinária e Zootecnia, Belo Horizonte, v. 57, n. 3, p. 374-379, 2005.
LOPES, M. A.; SAMPAIO, A. A. M. Manual do confinador de bovinos de corte. Jaboticabal: FUNEP, 1999. 106 p.

MATSUNAGA, M.; BEMELMANS, P. F.; TOLEDO, P. E. N. de; DULLEY, R. D.; OKAWA, H.; PEDROSO, I. A. Metodologia de custo de produção utilizado pelo IEA. Agricultura em São Paulo, São Paulo, v. 23, n. 1, p. 123139, 1976.

NOGUEIRA, M. P. Importância da gestão de custos: curso online: módulo I: gestão de custos e avaliação de resultados. [S.1.]: Agripoint, 2004. 